\title{
POPULASI MAKSIMUM BERDASARKAN DAYA DUKUNG FISIK SAMPAH DI GILI AIR, LOMBOK UTARA, NTB
}

\author{
Jussac M Masjhoer *, Amalia Febryane Adhani Mazaya, Aditano Yani Retawimbi \\ Sekolah Tinggi Pariwisata Ambarrukmo Yogyakarta \\ *Email: jussacmaulana@stipram.ac.id
}

\begin{abstract}
MAXIMUM POPULATION BASED ON THE PHYSICAL SUPPORT OF WASTE IN GILI AIR, NORTH LOMBOK, NTB
\end{abstract}

Solid waste management that has implemented in Gili Air has not been able to cope optimally with the increase in waste volume originating from residents and tourists. As a consideration in optimizing the volume of waste that can be accommodated and managed, the carrying capacity approach can be used. The physical support of waste will be the basis for determining the maximum population on Gili Air. This research aims to measure the maximum population found in Gili Air based on the physical support of waste analysis. The key informants was given questions regarding the solid waste management system to obtain primary data, while secondary data obtained from related bureaus in the local government. The qualitative descriptive methods was used to analyze primary data from the interview, and carrying capacity and waste capacity analysis for secondary data. Waste management activities on the island limited to container and collection activities. The waste pile transported by barge to the landfill on the main island. The tourism business was imposed a levy tax according to the volume of waste generated. The potential of recyclable waste is lower than the potential for generation, so the carrying capacity of waste is relatively low with an index of 0,20 . The potential for piled waste that has not managed properly is $1,230.86 \mathrm{~kg}$ per day. Following the calculation results of the physical support of waste, the maximum population size that Gili Air can accommodate is 2,795 people per day. The excess number of tourists as many as 585 people per day causes the solid waste management system overwhelmed.

Keywords: Physical carrying capacity; Solid waste management; Small islands population; Marine tourism; Tourism impacts.

\section{PENDAHULUAN}

Gili Air merupakan destinasi wisata bahari favorit wisatawan di Kabupaten Lombok Utara, Nusa Tenggara Barat. Pascagempa hebat pada 29 Juli 2018, pelan tapi pasti, kunjungan wisatawan ke Gili Air mulai berangsur pulih. Tercatat terjadi peningkatan sebesar $40,2 \%$ atau sebanyak 14.307 orang pada bulan
September atau dua bulan pascagempa (Nukman, 2018). Meskipun secara ekonomi menguntungkan, meningkatnya jumlah kunjungan wisatawan juga turut berkontribusi kepada semakin meningkatnya volume sampah di lokasi tersebut. Kunjungan wisatawan ke tiga Gili di Lombok Utara ini mencapai hingga 350.000 orang per tahun (Yapeka, 2018). Jumlah wisatawan sebanyak itu memberikan kontribusi sampah yang 
cukup signifikan. Pada hari biasa jumlah sampah sebanyak 7-8 ton per hari, namun memasuki tahun baru 2018 sampah membludak menjadi 12-14 ton per hari (Lombokita, 2018). Sampah-sampah di Gili Air berasal dari limbah rumah tangga masyarakat, industri usaha pariwisata, dan diperparah dengan kesadaran dan kepedulian wisatawan dan masyarakat akan lingkungan yang rendah (Priherdityo, 2017; Syafari, 2018). Pengembangan pariwisata acapkali mengesampingkan keberadaan dan pengelolaan sampah padat yang layak padahal pariwisata memproduksi sampah lebih banyak daripada aktivitas lainnya (Arbulú et al., 2015).

Persoalan pengelolaan sampah padat di destinasi wisata dapat menjadi bumerang bagi industri pariwisata itu sendiri. Hal ini dikarenakan pariwisata harus menunjukkan sisi cantik dan indah sebagai daya tarik, bukan sebaliknya. Wisatawan menghendaki pantai yang bebas sampah dan pemandangan yang indah (Williams et al., 2016). Sampah padat dan polusi lain akan mengancam keindahan alam, kualitas hidup penduduk, daya tarik wisata, dan pencapaian ekonomi (Kapmeier and Gonçalves, 2018). Keberadaan sampah yang tidak tertangani akan mempengaruhi kebersihan pantai (Rangel-Buitrago et al., 2019), pemandangan pantai (Corraini et al., 2018; Orock, 2017), penyebab utama degradasi pantai (Nachite et al., 2019), dan aktivitas pariwisata (AsensioMontesinos et al., 2019).

Gili Air memiliki luas \pm 175 ha, sehingga dikategorikan sebagai pulau kecil (Indonesia, 2007). Pemanfaatan lahan di pulau kecil sebaiknya maksimal sebesar 50\% dari seluruh luas dan 30\% untuk pulau sangat kecil (Bengen, 2006). Pembangunan di Gili Air terus berkembang, khususnya berupa fasilitas pariwisata dengan total pemanfaatan lahan sebesar $28.5 \%$ dari luas Gili Air
(Kurniawan et al., 2016). Gili Air memenuhi kriteria untuk menyelenggarakan pengelolaan sampah, karena terdapat penduduk yang menetap dan aktivitas yang menghasilkan sampah (Direktur Jenderal Cipta Karya, 2016).

Aktivitas pariwisata di Gili Air menambah produksi sampah padat selain yang diproduksi oleh penduduk setempat. Wisatawan dalam konteks pengelolaan sampah padat dianggap sebagai potensi timbulan, sehingga keberadaannya perlu diperhitungkan. Peningkatan volume sampah akibat lonjakan kedatangan wisatawan di musim tertentu menambah beban pengelolaan sampah padat yang ada (Saat and Saputra, 2019). Di Pulau Menorca, Spanyol, peningkatan populasi wisatawan sebesar $1 \%$ mengakibatkan kenaikan sebesar $0.282 \%$ dari keseluruhan sampah padat (Mateu-Sbert et al., 2013). Bahkan di Kepulauan Baleric, Spanyol, diperkirakan mengalami kenaikan produksi sampah padat hingga $15 \%$ yang berasal dari wisatawan (Estay-Ossandon and Mena-Nieto, 2018). Sampah yang dihasilkan dari pariwisata di Pulau-pulau Kecil (PPK) sebagian besar berupa sampah organik. Pulau Kapas, Malaysia menghasilkan sampah mencapai $100 \mathrm{~kg}$ per hari dengan komposisi sebesar 70\% berupa sampah organik (Aisyah and Saputra, 2019), komposisi yang tidak jauh berbeda dengan Pulau Perhentian dengan sampah organik lebih dari $72 \%$ (Saat et al., 2019). Perlu adanya solusi untuk mengoptimalkan pengelolaan sampah padat yang sudah ada di pulau kecil.

Daya dukung dapat diartikan sebagai kemampuan optimal suatu sistem untuk mentolerir gangguan dan mendukung aktivitas atau kegiatan pada tingkatan tertentu. Penerapan konsep daya dukung lingkungan dapat dilakukan pada kondisi populasi atau sumberdaya sesuai dengan tujuan yang ingin diraih. Namun demikian, penentuan daya dukung lingkungan membutuhkan nilai justifikasi 
untuk aktivitas yang dioptimalkan (Inglis et al., 2000). Pemanfaatan konsep daya dukung fisik dalam pariwisata sering digunakan untuk menentukan jumlah wisatawan, aktivitas, dan luasan area wisata (Cupul-Magaña and RodríguezTroncoso, 2017; Manafi et al., 2009; Muhsoni and Efendy, 2016; Romadhon et al., 2013). Sampah padat bila dipandang sebagai entitas mutlak dari aktivitas manusia di pulau kecil, maka keberadaannya dapat diperhitungkan dalam sebuah konsep daya dukung. Konsep daya dukung sampah akan memperhitungkan volume sampah yang mampu ditampung secara optimal oleh Gili Air sehingga tidak mengurangi fungsi ekologis maupun estetika di lokasi tersebut, dengan kata lain jumlah volume sampah perhari yang dapat ditangani oleh sistem pengelolaan sampah padat yang ada. Kemampuan ekosistem pulau dalam menyerap limbah yang dihasilkan oleh pembangunan menjadi penentu daya dukung PPK (Manafi et al., 2009). Disamping itu, penyusunan strategi pengelolaan sampah padat yang efektif di destinasi wisata perlu memperkirakan musim kedatangan wisatawan (MateuSbert et al., 2013).

Gili Air sebagai pulau kecil dengan segala keterbatasannya, khususnya ruang fisik, harus mampu menyelesaikan masalah sampah secara mandiri, dan konsep daya dukung sendiri telah berkembang menjadi parameter yang penting untuk mengembangkan alat manajemen yang efektif dalam melindungi lingkungan. Analisa daya dukung fisik sampah perlu dilakukan untuk memperhitungkan volume sampah yang mampu ditampung secara optimal oleh Gili Air sehingga tidak mengurangi fungsi ekologis maupun estetika di lokasi tersebut, dengan kata lain jumlah volume sampah perhari yang dapat ditangani oleh sistem pengelolaan sampah padat yang tersedia. Penelitian ini bertujuan untuk menemukan angka optimum dari daya dukung fisik sampah di Gili Air. Selanjutnya, hasil angka tersebut dijadikan sebagai dasar dalam penentuan jumlah maksimum populasi yang mampu diakomodasi oleh sistem pengelolaan sampah padat yang ada.

\section{METODOLOGI}

\subsection{Lokasi Penelitian}

Gili Air, Kabupaten Lombok Utara, Nusa Tenggara Barat dijadikan sebagai lokasi penelitian dengan pertimbangan bahwa pulau ini adalah salah satu destinasi wisata bahari yang berkembang pesat dengan populasi penduduk terbesar diantara kedua Gili lainnya. 


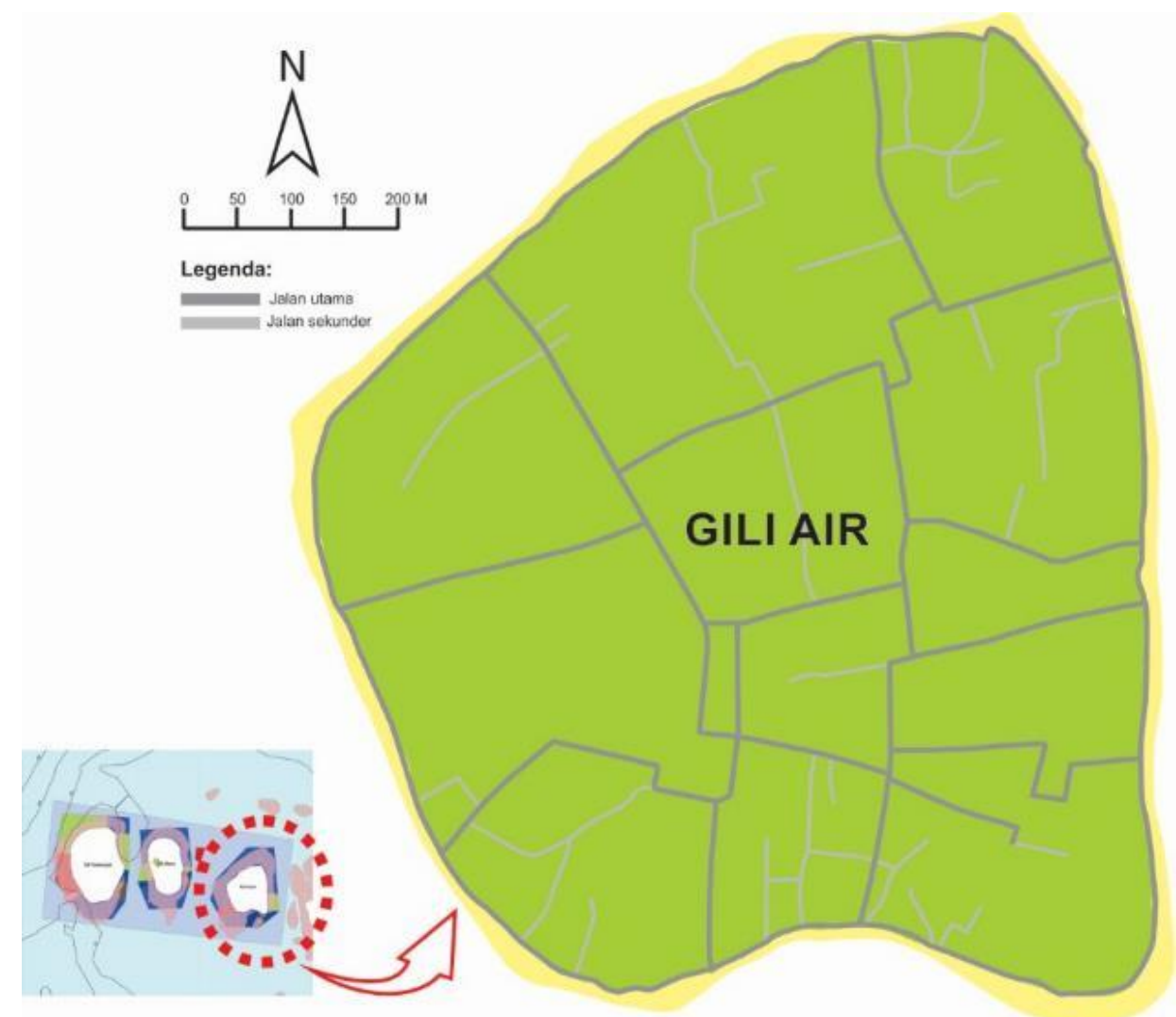

Gambar 1.

Peta Lokasi Penelitian (KKP, n.d.)

\subsection{Pengumpulan Data}

Data primer didapatkan melalui proses wawancara kepada narasumber kunci terkait pengelolaan sampah di Gili Air yaitu Kepala UPT BLUD Persampahan Dinas Lingkungan Hidup Perumahan dan Kawasan Permukiman Kab. Lombok Utara, Kepala Desa Gili Indah, dan Kelompok Swadaya Masyarakat (KSM) Gili Air. Pertanyaan yang diajukan terkait sistem pengelolaan sampah padat yaitu teknis operasional, kelembagaan, pembiayaan, dan peran serta masyarakat. Data sekunder penelitian ini berupa data jumlah penduduk, jumlah kunjungan wisatawan, data persampahan, dan data Rencana Tata Ruang Wilayah di Gili Air yang didapatkan dari Pemerintah Desa Gili Indah, UPT BLUD Persampahan, dan Dinas Pariwisata Kabupaten Lombok Utara. Data primer dan sekunder yang telah didapatkan kemudian diinventarisir serta diolah untuk menjadi database penelitian.

\subsection{Analisis data}

Data primer dari proses wawancara selanjutnya dianalisis menggunakan metode deskriptif kualitatif. Penelitian Paramita et al., (2018) menjadi acuan dalam melakukan analisis data sekunder untuk menghitung daya dukung dan kapasitas tampung Depo Gili Air, sedangkan analisis daya dukung fisik sampah didapatkan melalui modifikasi rumus daya dukung kawasan oleh (Yulianda, 2007). Potensi timbulan sampah yang dihasilkan setiap hari adalah jumlah penduduk dan wisatawan dikalikan rata-rata sampah yang dihasilkan setiap hari. Potensi timbulan sampah yang dihasilkan dapat dihitung sebagai berikut:

$$
P T S=N \times \bar{x}
$$


Keterangan:

PTS: Potensi timbulan sampah (kg/hari)

$\mathrm{N}$ : Jumlah penduduk (orang)

$\bar{x}$ : Rata-rata sampah dihasilkan (kg/hari)

$$
\text { PTSo }=\text { PTS } \times \text { Persentase So }
$$

Keterangan:

PTSo: Potensi Timbulan Sampah Organik PTS: Potensi Timbulan Sampah

Persentase So : $55 \%$

$$
\text { PTSa }=\text { PTS } \times \text { Persentase Sa }
$$

Keterangan:

PTSa: Potensi timbulan sampah anorganik yang dapat di daur ulang

PTS: Potensi Timbulan Sampah

Persentase Sa : $20 \%$

Selanjutnya Khairunisa (2011), menyatakan bahwa daya dukung depo dapat dihitung dengan membandingkan potensi sampah terolah dan terangkut dengan realisasi potensi pemanfaatan. Daya dukung lingkungan yang tinggi akan didapatkan bila potensi yang dimiliki lebih kecil dibandingkan potensi yang termanfaatkan, dan sebaliknya daya dukung yang rendah ditunjukkan dengan potensi yang dimiliki lebih besar dari potensi yang termanfaatkan. Berikut adalah rumus matematis indeks daya dukung lingkungan:

Keterangan:

$$
I D D S=\frac{P T S a}{P T S}
$$

PTSa: Potensi timbulan sampah anorganik yang dapat di daur ulang

PTS: Potensi Timbulan Sampah

Selisih kapasitas sampah dapat diketahui melalui pengurangan antara total kapasitas pengelolaan dengan total timbulan sampah. Daya dukung TPS dianggap belum terlampaui bila selisih kapasitas sampah bernilai $\geq 0$, sebaliknya bila selisih kapasitas sampah $\leq 0$ maka daya dukung TPS telah terlampaui. Daya dukung fisik sampah dalam penelitian ini yaitu jumlah orang optimal yang dapat ditampung dan melakukan aktivitas di lokasi tertentu dengan melihat sampah padat yang dihasilkan sehingga lingkungan tidak mengalami degradasi ataupun pencemaran olehnya. Daya dukung fisik sampah didapatkan dari modifikasi rumus daya dukung kawasan oleh (Yulianda, 2007):

$$
\text { DDFS }=K \times\left(\frac{\mathrm{St}}{\mathrm{Sp} \mathrm{tot}}\right) \times\left(\frac{\mathrm{Lt}}{\mathrm{Lp}}\right)
$$

Keterangan:

DDFS: Daya dukung fisik sampah

$\mathrm{K}$ : Potensi ekologis pengunjung/penduduk penghasil sampah (orang)

Kp: Kapasitas Total TPS (kg/hari)

St: Total Sampah terangkut (kg/hari)

Sp tot: Sampah potensi yang dihasilkan pengunjung dan penduduk dalam penelitian ini berkisar antara 2,5-2,75 (kg/orang/hari)

Lp: Luas unit kawasan optimal untuk satu orang $\left(\mathrm{m}^{2}\right)$

Lt: Luas kawasan yang dimanfaatkan $\left(\mathrm{m}^{2}\right)$

Hasil dari daya dukung fisik sampah adalah satuan orang/hari yang dapat menghasilkan sampah optimal dalam satu pulau. Hasil ini sudah mempertimbangkan sampah marine debris dan juga sampah domestik masyarakat setempat. Informasi pendukung berupa luas area termanfaatkan didapatkan melalui analisis GIS. Sementara sampah total yang dihasilkan dalam satu pulau adalah sebesar 0,6-0,7 kg/orang/hari. Untuk mengetahui daya dukung fisik sampah di Gili Air adalah dengan mengalikan jumlah penduduk dan wisatawan perhari dengan jumlah sampah yang dihasilkan orang dalam kg/orang/hari, kemudian dengan mencari selisih antara kondisi eksisting dengan per sebagai berikut.

$$
\text { Selisih }=\text { DDFS }-(\mathrm{Jp}+\mathrm{Jw})
$$


Keterangan:

DDFS: Daya dukung fisik sampah (orang/hari)

Jp: Jumlah penduduk (orang)

Jw: Jumlah wisatawan (orang/hari)

Selisih yang bernilai positif menunjukkan orang/wisatawan yang dapat ditambahkan/yang dapat melakukan wisata di Gili Air dan dapat dikatakan aktivitas di Gili Air belum melebihi daya dukung fisik. Sedangkan jika hasilnya negatif maka telah melebihi daya dukung dan harus dibatasi jumlah wisatawan yang masuk agar tidak terjadi kerusakan kawasan akibat timbulan sampah. Hasil analisis dari penelitian ini kemudian dapat digunakan sebagai input dalam menentukan jumlah populasi yang dapat ditampung oleh Gili Air.

\section{HASIL DAN PEMBAHASAN}

\subsection{Sistem pengelolaan sampah padat di Gili Air}

Secara umum, sampah padat berasal dari rumah-rumah di pemukiman warga dan usaha pariwisata yang tersebar di Gili Air. Sumber sampah terbesar berasal dari restoran dan akomodasi (villa, resort, hotel) dengan material organik sebagai komposisi sampah yang paling banyak ditemukan. Sampah anorganik yang ditimbulkan berupa botol minuman, botol plastik, kaca, sampah plastik, dan gelas. Volume timbulan sampah di Gili Air untuk low season sekitar 2 ton dan saat high season sekitar 3-4 ton. Sampah yang dihasilkan dari pariwisata di pulau-pulau kecil sebagian besar berupa sampah organik (Aisyah and Saputra, 2019; Saat et al., 2019).

Gili Air hingga saat ini belum memiliki infrastruktur persampahan yang memadai sehingga secara teknis operasional, aktivitas pengelolaan sampah di pulau ini terbatas di aktivitas pewadahan dan pengumpulan. Pewadahan sampah menggunakan tempat sampah biasa tanpa ada pemisahan berdasarkan jenis sampah. Sampah yang dihasilkan kemudian dimasukkan ke dalam kantong plastik besar, kecuali untuk botol kaca, gelas, dan pecahan kaca, yang kemudian ditaruh di depan rumah/ restoran/ hotel atau di jalan jalur utama penggumpulan.

Proses pengumpulan sampah dari sumber sampah dilakukan oleh KSM Gili Air menggunakan cidomo (kereta kuda) dan kendaraan bak roda 3. Pengumpulan dilakukan saat subuh hingga pukul 07.00 WITA setiap hari. Hal ini dilakukan karena Gili Air sendiri tidak memiliki TPST, namun hanya sebuah titik dipinggir pantai yang disebut Depo di sisi Timur Gili Air yang difungsikan sebagai lokasi sementara pengumpulan sampah. Tanpa adanya struktur fisik yang menampung sampah di depo, mengakibatkan luberan sampah saat kondisi high season dan terseret ombak ke laut. Di depo dengan areal seluas $20 \mathrm{~m} 2 \mathrm{ini}$, sampah yang masih memiliki nilai ekonomi dipilah oleh pihak Dinas Lingkungan Hidup. Sampah kemudian diangkut menggunakan kapal tongkang menuju umbak belik di pulau utama yaitu Pulau Lombok. Di Umbak Belik, sampah langsung diangkut menuju TPA Jugil untuk melalui pemrosesan akhir. 


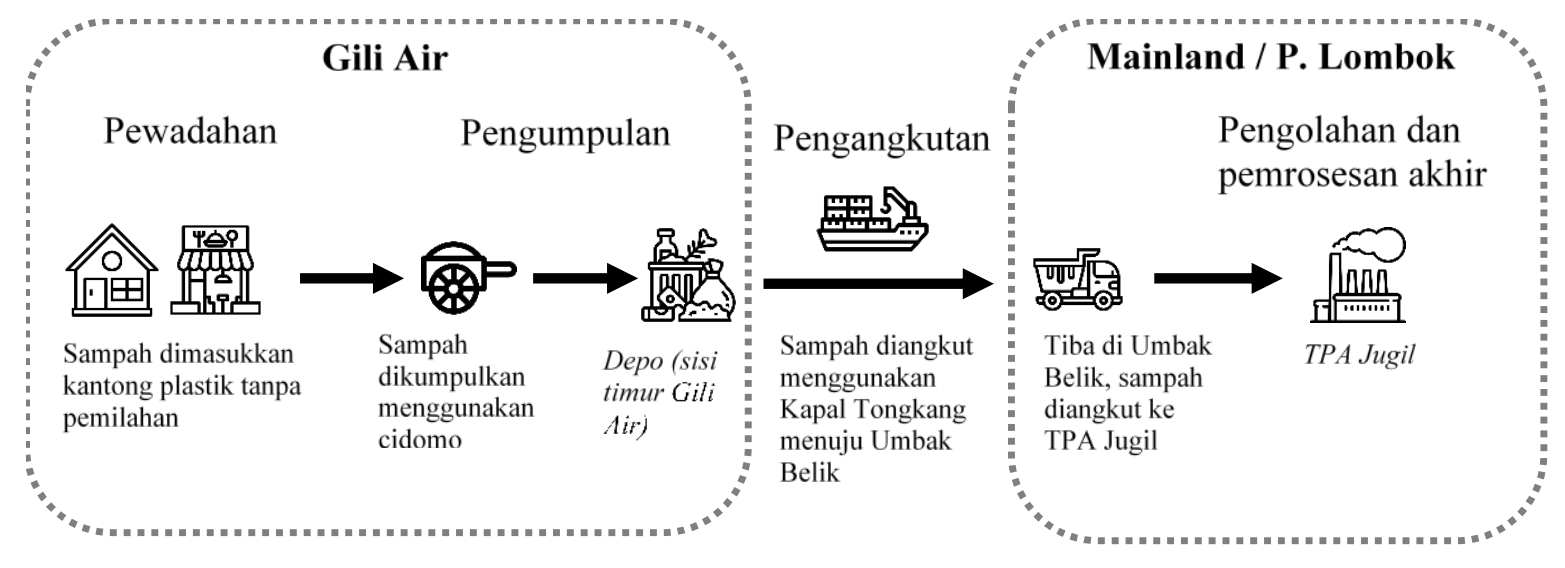

Gambar 2.

Bagan teknis operasional pengelolaan sampah padat di Gili Air (sumber: olahan data, 2020)

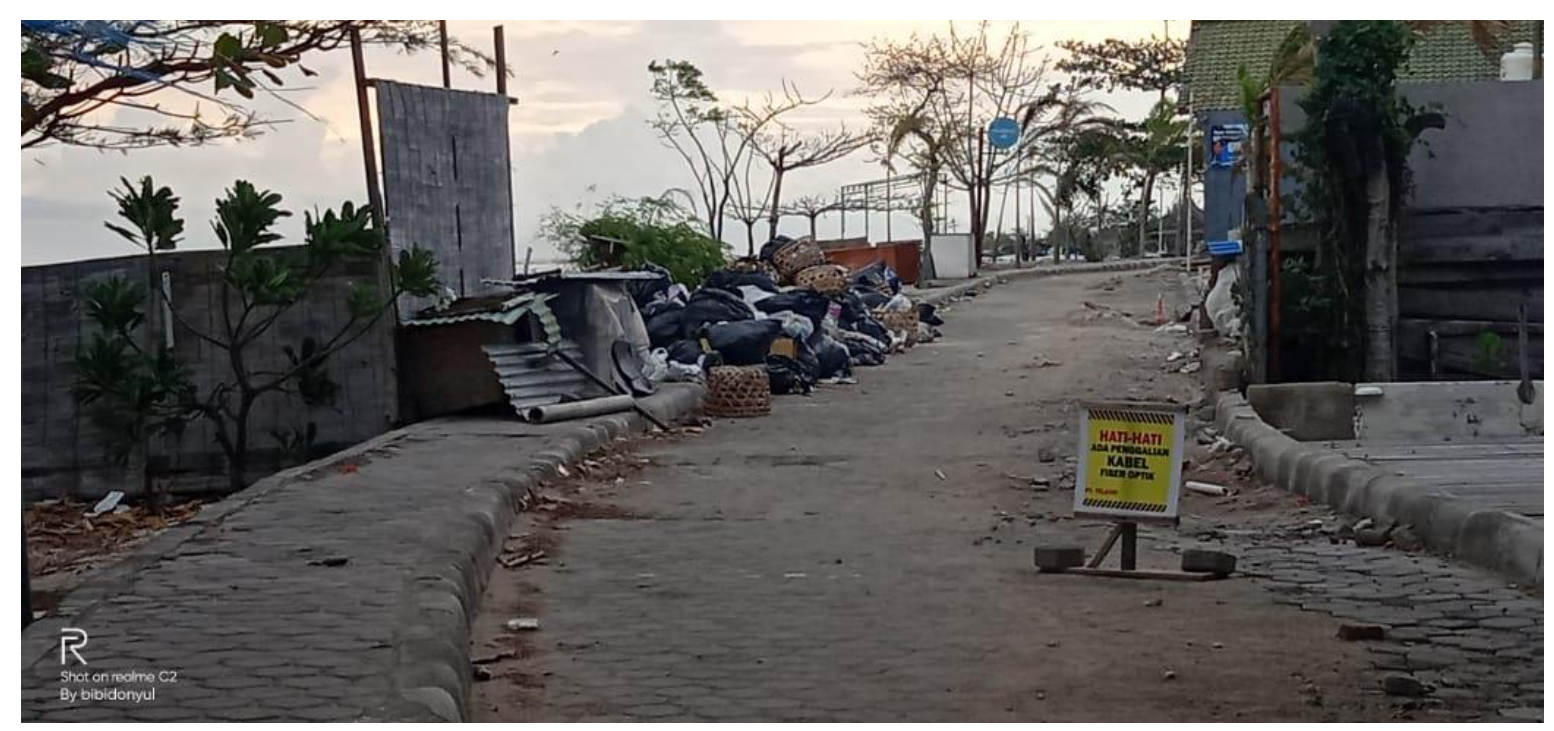

Gambar 3.

Depo sampah di sisi Timur Gili Air (sumber: dokumentasi penelitian, 2020)

Sampah padat secara formal di kelola oleh Kelompok Swadaya Masyarakat (KSM) Gili Air dan Dinas Lingkungan Hidup Kabupaten Lombok Utara. KSM terbentuk sejak tahun 2013 yang dibentuk oleh kepala Desa dengan anggota sebanyak 4 orang. KSM Gili Air bertugas untuk melakukan pengumpulan dan pemungutan retribusi dari sumber sampah. Operasional pengumpulan sampah oleh KSM menggunakan jasa cidomo sebanyak 8 buah dan satu buah kendaraan angkut roda tiga. Dinas Lingkungan Hidup bertempat di pulau utama, dan bertugas untuk mengangkut sampah dari Gili Air menuju pulau utama. DLH memiliki personil sejumlah 23 orang yang bertugas untuk mengambil sampah dari depo di Gili Air menuju TPA Jugil. Operasional pengangkutan dilakukan mulai pukul 08.00 WITA dengan menggunakan 1 buah kapal tongkang dan 2 buah dump truk. Proses pengangkutan dilakukan sebanyak dua kali dalam kondisi normal sedangkan di masa pandemi ini hanya 1 kali. Selain KSM dan DLH, pengumpulan juga dilakukan oleh 
pemulung untuk sampah yang masih memiliki nilai jual.

Pembiayaan pengelolaan sampah di Gili Air sepenuhnya berasal dari retribusi sampah yang dibebankan kepada usaha pariwisata, sedangkan untuk penduduk tidak dibebankan biaya retribusi. Teknis pemungutan dan besaran retribusi menjadi wewenang KSM sesuai dengan ijin operasional dari Bupati. Berdasarkan kesepakatan bersama, tarif retribusi disesuaikan dengan jumlah sampah yang dihasilkan oleh usaha pariwisata. Semakin besar volume sampah yang dihasilkan maka semakin besar pula retribusi yang harus dibayarkan. Besaran retribusi sampah yang ditarik untuk hotel dan restoran sebesar Rp 100-150 ribu dan toko kelontong sebesar Rp 50-100 ribu. Salah satu beban pembiayaan yang dikeluarkan yaitu untuk membayar sewa jasa cidomo dengan total pengeluaran sebesar $\mathrm{Rp} 21$ 23 juta perbulan.

Masyarakat di Gili Air sudah pernah mendapatkan pelatihan terkait pengelolaan sampah yang diselenggarakan oleh DLH maupun KSM dengan sasaran ibu PKK dan LSM setempat. Topik pelatihan yang diberikan yaitu 3R (Reduce, Reuse, Recycle) dan pembuatan kompos dari sampah organik. Edukasi program 3R masih belum terpadu antara stakeholder dan masih dilakukan berdasarkan organisasi mereka sendiri. Hasil dari edukasi yang telah dilakukan, masyarakat Gili Air mulai sadar terkait 3R terlebih di saat pandemi Covid 19. Meskipun demikian, baru sebagian kecil masyarakat sudah mulai aktif didalam mengumpulkan sampah dan mulai memilah antara sampah organik dan organik. Menurut Ramadhanti (2020), pengelolaan sampah berbasis masyarakat membutuhkan dukungan fasilitas persampahan yang mumpuni dan peningkatan kesadaran lingkungan. Di sisi pengusaha, pemisahan hanya dilakukan untuk botol kaca dan plastik yang dikumpulkan kemudian diambil oleh pemulung, sedangkan sisa sampah lainnya dicampur tanpa pemilahan. Perlu adanya solusi untuk mengoptimalkan pengelolaan sampah padat yang sudah ada di pulau kecil. Pengurangan dan pencegahan sampah menjadi metode paling efektif dalam hirarki pengelolaan sampah padat (Yakubu and Zhou, 2019).

\subsection{Analisis Daya Dukung dan Kapasitas Tampung Sampah}

Sampah yang dihasilkan oleh total penduduk dan wisatawan dalam satu hari disebut dengan potensi timbulan sampah. Berdasarkan hasil penelitian, total potensi timbulan sampah yang dapat dihasilkan di Gili Air adalah sebesar 2.230,86 kg/hari. Komposisi potensi timbulan sampah terdiri dari $55 \%$ berupa sampah organik atau sebesar $1.226,97 \mathrm{~kg} / \mathrm{hari}, 20 \%$ berupa sampah anorganik atau sebesar 446,17 $\mathrm{kg} / \mathrm{hari}$, dan $25 \%$ sisanya merupakan sampah dengan jenis lain-lain. Indeks daya dukung sampah dinilai semakin tinggi bila mendekati angka 1. Indeks daya dukung sampah yang dihitung menggunakan rumus daya dukung fisik menunjukkan nilai 0,20. Hal tersebut menunjukkan potensi pemanfaatan sampah yang dapat didaur ulang lebih rendah dibanding potensi timbulan, oleh karena itu daya dukung sampah di Gili Air relatif rendah. Hal ini diperkuat dengan perhitungan selisih kapasitas sampah dengan sampah terangkut setiap harinya yang menunjukkan nilai $-1.230,86 \mathrm{~kg} / \mathrm{hari}$. Perhitungan tersebut menunjukkan ada potensi sampah yang tertimbun setiap harinya di Gili Air yang harus dikelola dengan baik.

Aktivitas pariwisata di Gili Air menambah produksi sampah padat selain yang diproduksi oleh penduduk setempat. Wisatawan dalam konteks pengelolaan sampah padat dianggap sebagai potensi timbulan, sehingga keberadaannya perlu diperhitungkan. Lonjakan jumlah 
wisatawan di musim tertentu turut menambah beban pengelolaan sampah padat yang ada (Saat and Saputra, 2019). Di Pulau Menorca, Spanyol terjadi kenaikan sebesar produksi sampah sebesar 0.282\% (Mateu-Sbert et al., 2013) dan Kepulauan Baleric, Spanyol mengalami kenaikan hingga 15\% (EstayOssandon and Mena-Nieto, 2018). Penambahan timbulan sampah padat dari wisatawan perlu disikapi dengan meningkatkan kualitas sistem pengelolaan sampah padat yang ada.

Tabel 1. Perhitungan Potensi Timbulan Sampah di Desa Gili Air

\begin{tabular}{lr}
\hline \multicolumn{1}{c}{ Parameter } & \multicolumn{1}{c}{ Jumlah } \\
\hline Potensi Timbulan Sampah (kg/hari) & $2.230,86$ \\
\hline Potensi Timbulan Sampah Organik (kg/hari) & $1.226,97$ \\
\hline P. Timbulan sampah anorganik yang dapat didaur ulang (kg/hari) & 446,17 \\
\hline Indeks Daya Dukung Sampah & 0,20 \\
\hline Selisih kapasitas sampah (kg/hari) & $-1.230,86$ \\
\hline
\end{tabular}

Sumber: Olahan Data, 2020

\subsection{Analisis Daya Dukung Fisik Sampah}

Pada tahun 2014, jumlah penduduk sebesar 1,606 orang dan di tahun yang sama jumlah kunjungan wisatawan tercatat sebanyak 85,156 orang atau ratarata 1,774 orang per hari di saat weekend. Daya dukung fisik sampah didasarkan pada perhitungan kapasitas total Depo di Gili Air dengan potensi sampah yang dihasilkan perharinya serta mempertimbangkan luas wilayah yang dapat dimanfaatkan untuk aktivitas domestik dan pariwisata. Perhitungan daya dukung fisik di Gili Air menunjukkan angka sebesar 2.795 orang/hari. Hasil perhitungan tersebut mengkonfirmasi hasil perhitungan daya dukung dan kapasitas tampung sampah. Bila dibandingkan dengan jumlah penduduk dan wisatawan, maka kondisi daya dukung fisik di Gili Air telah kelebihan sebanyak 585 orang per hari. Berdasarkan daya dukung fisik sampah, maka jumlah penduduk dan sampah padat yang dihasilkan telah dapat di atasi oleh sistem pengelolaan sampah padat yang ada dengan tambahan jumlah wisatawan sebanyak 1.189 orang. Kelebihan jumlah wisatawan sebesar $49 \%$ setiap hari menyebabkan potensi sampah tertimbun dan akhirnya menjadi beban sistem pengelolaan sampah yang telah diterapkan selama ini. Dapat diartikan bahwa jumlah penduduk dan wisatawan setiap hari yang terdapat di Gili Air tidak sebanding dengan kapasitas persampahan yang selama ini dijalankan oleh KSM dan DLH KLU. Hal ini mengakibatkan terbengkalainya sampah atau tidak terangkutnya sampah-sampah yang ditimbulkan oleh aktivitas manusia di Gili Air.

Daya dukung fisik sampah dapat ditingkatkan dengan memperbaiki kualitas sistem pengelolaan sampah padat yang terdapat di Gili Air melalui beberapa skenario. Skenario pertama yaitu melalui peningkatan nilai total sampah terangkut dengan cara menambah ritase pengangkutan atau jumlah armada tongkang yang membawa sampah padat dari depo menuju mainland. Perbaikan di proses pengangkutan tersebut dapat juga diringankan dengan menerapkan pengurangan sampah (reduce, reuse, recycle) di sumber sampah. Idealnya, sampah padat yang dibawa keluar dari Gili Air adalah sampah padat yang sudah tidak dapat dikelola atau diolah oleh 
sistem persampahan di Gili Air. pengomposan sampah organik sebagai Tercampurnya sampah padat sejak dari solusi efektif dalam pengelolaan sampah sumber sampah tanpa ada pemisahan, padat (Aisyah and Saputra, 2019). menjadi beban tambahan bagi kapasitas Skenario terakhir yaitu dengan melakukan depo serta keseluruhan sistem pengelolaan pembatasan terhadap jumlah wisatawan sampah padat. Oleh karena itu, pulau kecil yang berkunjung setiap hari ke Gili Air. dapat menerapkan daur ulang dan

Tabel 2. Perhitungan Daya Dukung Fisik Pesampahan di Gili Air

\begin{tabular}{lr}
\hline \multicolumn{1}{c}{ Parameter } & Jumlah \\
\hline Jumlah penduduk (orang) & 1.606 \\
\hline Jumlah wisatawan (orang/tahun) & 85.156 \\
\hline Jumlah wisatawan (orang/hari) & 1.774 \\
\hline Potensi ekologis pengunjung (orang) (K) & 1 \\
\hline Kapasitas total TPS (kg/hari) (Kp) & 1.000 \\
\hline Total sampah terangkut (kg/hari) (St) & 5.000 \\
\hline Sampah potensi yang dihasilkan (kg/orang/hari) (Sp) & 0,66 \\
\hline Sampah potensi total yang dihasilkan (kg/orang/hari) (Sp tot) & $2.230,86$ \\
\hline Luas total kawasan (m2) & 1.750 .000 \\
\hline Luas kawasan yg dimanfaatkan 28,5\% (m $\left.{ }^{2}\right)(\mathrm{Lt})$ & 498.750 \\
\hline Luas unit kawasan optimal untuk satu orang (m $\left.{ }^{2}\right)(\mathrm{Lp})$ & 400 \\
\hline Daya Dukung Fisik (orang/hari) & 2.795 \\
\hline Selisih daya dukung fisik dengan kondisi eksisting (orang/hari) & -585 \\
\hline Sumber: Olahan Data, 2020 &
\end{tabular}

\section{SIMPULAN}

Gili Air memiliki aktivitas pariwisata yang menghasilkan sampah padat diluar aktivitas domestik penduduk setempat sehingga memerlukan penyelenggaraan pengelolaan sampah padat. Keterbatasan luas wilayah yang dimiliki oleh pulau kecil memerlukan perencanaan pengelolaan sampah padat yang memperhitungkan konsep daya dukung. Konsep daya dukung sampah memperhitungkan volume sampah yang mampu ditampung secara optimal dan dapat ditangani oleh sistem pengelolaan sampah padat yang ada tanpa mengurangi fungsi ekologis maupun estetika di Gili Air.

Indeks daya dukung sampah di Gili Air menunjukkan nilai 0,20 yang menunjukkan potensi pemanfaatan sampah yang dapat didaur ulang lebih rendah dibanding potensi timbulan, sehingga daya dukung sampah di Gili Air relatif rendah. Hal tersebut diperkuat dengan hasil perhitungan yang menunjukkan adanya potensi sampah yang tertimbun dan belum dikelola dengan baik setiap hari sebesar 1.230,86 kg. Daya dukung fisik sampah di Gili Air hanya mampu mengatasi populasi sebanyak 2.795 orang per hari. Kelebihan sebanyak 585 orang per hari yang berasal dari wisatawan menjadikan sampah padat tidak tertangani. Hasil perhitungan dan analisis dalam penelitian ini mampu mengkonfirmasi bahwa jumlah populasi yang berlebih di Gili Air menyebabkan sistem pengelolaan sampah padat yang telah ada menjadi kewalahan.

Analisis daya dukung fisik sampah dapat menjelaskan populasi maksimum yang dapat menghasilkan sampah dalam 
sebuah pulau. Namun, analisis ini hanya cocok digunakan untuk pulau kecil yang memiliki aktivitas pariwisata didalamnya sehingga memerlukan sistem pengelolaan sampah padat. Perhitungan daya dukung fisik sampah akan lebih akurat bila menggunakan data primer untuk timbulan sampah padat. Penelitian lebih lanjut dapat dilakukan terhadap destinasi wisata bahari berbasis pulau kecil sebagai pembanding dan penyempurnaan model yang telah ada.

\section{DAFTAR PUSTAKA}

Aisyah, S., Saputra, J., 2019. The sustainability of solid waste management on Kapas Island, Terengganu, Malaysia. Int. J. Innov. Creat. Chang. 9, 241-249.

Arbulú, I., Lozano, J., Rey-Maquieira, J., 2015. Tourism and solid waste generation in Europe: A panel data assessment of the Environmental Kuznets Curve. Waste Manag. 46, 628-636.

https://doi.org/10.1016/j.wasman.201 5.04.014

Asensio-Montesinos, F., Anfuso, G., Corbí, H., 2019. Coastal scenery and litter impacts at Alicante (SE Spain): management issues. J. Coast. Conserv. 23, 185-201. https://doi.org/10.1007/s11852-0180651-8

Bengen, D.G., 2006. Menguak Realitas dan Urgensi Pengelolaan Berbasis Eko-sosio Sistem Pulau. Pusat Pembelajaran dan Pengembangan Pesisir dan Laut (P4L).

Corraini, N.R., de Souza de Lima, A., Bonetti, J., Rangel-Buitrago, N., 2018. Troubles in the paradise: Litter and its scenic impact on the North Santa Catarina island beaches, Brazil.
Mar. Pollut. Bull. 131, 572-579. https://doi.org/10.1016/j.marpolbul.2 018.04.061

Cupul-Magaña, A.L., RodríguezTroncoso, A.P., 2017. Tourist carrying capacity at Islas Marietas National Park: An essential tool to protect the coral community. Appl. Geogr. 88, 15-23. https://doi.org/10.1016/j.apgeog.2017 .08 .021

Direktur Jenderal Cipta Karya, 2016. Tata Cara Penyelenggaraan Sistem Pegelolaan Sampah di Pulau Kecil. Kementerian Pekerjaan Umum dan Perumahan Rakyat.

Estay-Ossandon, C., Mena-Nieto, A., 2018. Modelling the driving forces of the municipal solid waste generation in touristic islands. A case study of the Balearic Islands (2000-2030). Waste Manag. 75, 70-81. https://doi.org/10.1016/j.wasman.201 7.12 .029

Indonesia, R., 2007. Undang-Undang Nomor 27 Tahun 2007 tentang Pengelolaan Wilayah Pesisir dan Pulau Kecil. Lembaran Negara Republik Indonesia Tahun 2007 Nomor 84.

Inglis, G., Hayden, B., Ross, A., 2000. An overview of factors affecting the carrying capacity of coastal embayments for mussel culture 38 .

Kapmeier, F., Gonçalves, P., 2018. Wasted paradise? Policies for Small Island States to manage tourismdriven growth while controlling waste generation: the case of the Maldives. Syst. Dyn. Rev. 34, 172221. https://doi.org/10.1002/sdr.1607

Khairunisa, V., 2011. Analisis Daya Dukung Lingkungan dan Kelayakan Ekonomi Unit Pengolahan Sampah "Mutu Elok" di Perumahan Cipinang 
Elok Jakarta Timur. Bogor Agricultural University (IPB).

KKP, n.d. Zonasi TWP Gili Matra [WWW Document]. kkp.go.id. URL https://kkp.go.id/djprl/bkkpnkupang/ page/1981-zonasi-twp-gili-matra (accessed 2.6.21).

Kurniawan, F., Adrianto, L., Bengen, D.G., Prasetyo, L.B., 2016. Vulnerability assessment of small islands to tourism: The case of the Marine Tourism Park of the Gili Matra Islands, Indonesia. Glob. Ecol. Conserv. 6, 308-326. https://doi.org/10.1016/j.gecco.2016. 04.001

Lombokita, 2018. Sehari, 14 Ton Sampah Menumpuk di Gili Trawangan.

Manafi, M.R., Fahrudin, A., G Bengen, D., Boer, M., 2009. Aplikasi Konsep Daya Dukung untuk Pembangunan Berkelanjutan di Pulau Kecil (Sudi Kasus Pulau Kaledupa, Kabupaten Wakatobi). J. Ilmu-ilmu Perair. dan Perikan. Indones. 1, 63-71.

Mateu-Sbert, J., Ricci-Cabello, I., Villalonga-Olives, E., CabezaIrigoyen, E., 2013. The impact of tourism on municipal solid waste generation: The case of Menorca Island (Spain). Waste Manag. 33, 2589-2593.

https://doi.org/10.1016/j.wasman.201 3.08.007

Muhsoni, F.F., Efendy, M., 2016. Analisis Daya Dukung Pemanfaatan Pulau Gili Labak Dengan Menggunakan Sistem Informasi Geografis. Semin. Nas. Perikan. dan Kelaut. VI, Fak. Perikan. dan Ilmu Kelautan, Univ. Brawijaya Malang 1-6.

Nachite, D., Maziane, F., Anfuso, G., Williams, A.T., 2019. Spatial and temporal variations of litter at the Mediterranean beaches of Morocco mainly due to beach users. Ocean Coast. Manag. 179, 104846. https://doi.org/10.1016/j.ocecoaman. 2019.104846

Nukman, H., 2018. Alhamdulillah, Wisatawan Berdatangan Lagi ke Gili Trawangan.

Orock, O., 2017. The effects of littering on tourism in Limbe, the Southwest Region of Cameroon Orock, Stanley Orock Bachelor' $s$ thesis in Natural Resources Degree program in Sustainable Coastal Mangement Rasborg 2017 1-38.

Paramita, D., Murtilaksono, K., Manuwoto, M., 2018. Kajian Pengelolaan Sampah Berdasarkan Daya Dukung dan Kapasitas Tampung Prasarana Persampahan Kota Depok. J. Reg. Rural Dev. Plan. 2, 104. https://doi.org/10.29244/jp2wd.2018. 2.2.104-117

Priherdityo, E., 2017. Gili Trawangan Kesulitan Tangani Masalah Sampah Wisatawan.

Ramadhanti, F., 2020. Analisis Potensi Pengelolaan Sampah Berkelanjutan Berbasis Masyarakat di Desa Saribaye Nusa Tenggara Barat. ECOTROPHIC J. Ilmu Lingkung. (Journal Environ. Sci. 14, 37. https://doi.org/10.24843/EJES.2020.v 14.i01.p04

Rangel-Buitrago, N., Mendoza, A.V., Gracia C, A., Mantilla-Barbosa, E., Arana, V.A., Trilleras, J., ArroyoOlarte, H., 2019. Litter impacts on cleanliness and environmental status of Atlantico department beaches, Colombian Caribbean coast. Ocean Coast. Manag. 179, 104835. https://doi.org/10.1016/j.ocecoaman. 2019.104835

Romadhon, A., Yulianda, F., Bengen, 
D.G., Adrianto, L., 2013. Perencanaan Pembangunan Gugus Pulau Sapeken Secara Berkelanjutan: Penilaian Daya Dukung Kawasan Bagi Pengembangan Wisata. J. Tataloka $15, \quad 218$. https://doi.org/10.14710/tataloka.15.3 .218-234

Saat, S.A., Saputra, J., 2019. A study of sustainable management of solid waste in Perhentian Island, Malaysia. Opcion 35, 239-253.

Saat, S.A., Saputra, J., Jamin, R.M., Muhamad, R., Nawi, R.M., 2019. A study of supply chain management for sustainable solid waste plan in Perhentian Island, Terengganu. Int. J. Supply Chain Manag. 8, 1022-1029.

Syafari, Z., 2018. Polusi dari Pembakaran Sampah Ancam Wisata Gili Trawangan.

Williams, A.T., Rangel-Buitrago, N.G., Anfuso, G., Cervantes, O., Botero, C.M., 2016. Litter impacts on scenery and tourism on the Colombian north Caribbean coast. Tour. Manag. 55, 209-224. https://doi.org/10.1016/j.tourman.201 6.02.008

Yakubu, Y., Zhou, J., 2019. Novel approach to quantify municipal solid waste management hierarchy based on analytical hierarchy process. Int. J. Environ. Sci. Technol. 16, 18971908.

https://doi.org/10.1007/s13762-0181768-x

Yapeka, R., 2018. Sekilas Tentang "Bukit Sampah" Gili Trawangan [WWW Document].

URL https://yapeka.or.id/bukit-sampahgili-trawangan/

Yulianda, F., 2007. Ekowisata bahari sebagai alternatif pemanfaatan sumberdaya pesisir berbasis konservasi. Makalah Seminar Sains. 